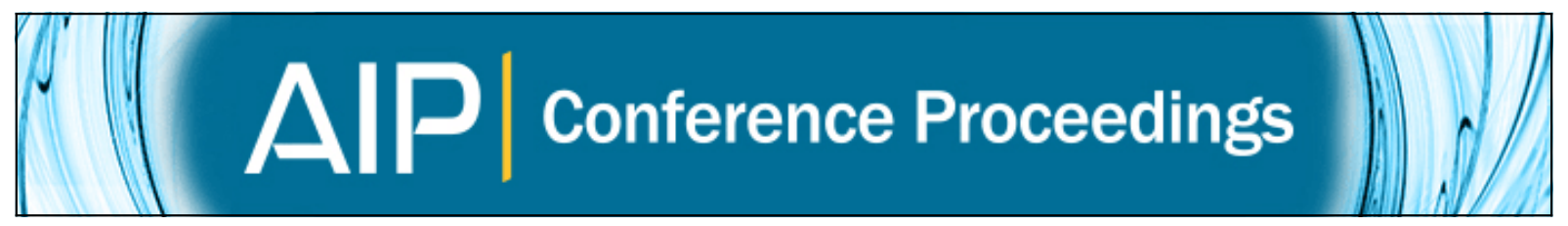

Measuring composition and growth of ion clusters of sulfuric acid, ammonia, amines and oxidized organics as first steps of nucleation in the CLOUD experiment

Siegfried Schobesberger, Arnaud Praplan, Heikki Junninen, Federico Bianchi, Gustaf Lönn, Mikael Ehn, Katrianne Lehtipalo, Josef Dommen, Sebastian Ehrhart, Alessandro Franchin, Ismael K. Ortega, Francesco Riccobono, Jonathan Duplissy, Matti Rissanen, Mikko Sipilä, Tuukka Petäjä, Markku Kulmala, Neil M. Donahue, Douglas R. Worsnop, and CLOUD Collaboration

Citation: AIP Conference Proceedings 1527, 298 (2013); doi: 10.1063/1.4803262

View online: http://dx.doi.org/10.1063/1.4803262

View Table of Contents: http://scitation.aip.org/content/aip/proceeding/aipcp/1527?ver=pdfcov Published by the AIP Publishing

Articles you may be interested in

Aerosol nucleation and growth in a mixture of sulfuric acid/alpha-pinene oxidation products at the CERN CLOUD chamber

AIP Conf. Proc. 1527, 322 (2013); 10.1063/1.4803268

Molecular steps of neutral sulfuric acid and dimethylamine nucleation in CLOUD AIP Conf. Proc. 1527, 302 (2013); 10.1063/1.4803263

Adsorption of organic molecules may explain growth of newly nucleated clusters and new particle formation AIP Conf. Proc. 1527, 258 (2013); 10.1063/1.4803253

Probing aerosol formation by comprehensive measurements of gas phase oxidation products AIP Conf. Proc. 1527, 185 (2013); 10.1063/1.4803234

The role of cluster energy nonaccommodation in atmospheric sulfuric acid nucleation J. Chem. Phys. 132, 024304 (2010); 10.1063/1.3291213 


\title{
Measuring Composition \& Growth of Ion Clusters of Sulfuric Acid, Ammonia, Amines \& Oxidized Organics as First Steps of Nucleation in the CLOUD Experiment
}

\author{
Siegfried Schobesberger ${ }^{\mathrm{a}}$, Arnaud Praplan ${ }^{\mathrm{a}}$, Heikki Junninen ${ }^{\mathrm{a}}$, Federico \\ Bianchi $^{\mathrm{b}}$, Gustaf Lönn ${ }^{\mathrm{a}}$, Mikael Ehn ${ }^{\mathrm{a}}$, Katrianne Lehtipalo ${ }^{\mathrm{a}}$, Josef \\ Dommen $^{\mathrm{b}}$, Sebastian Ehrhart ${ }^{\mathrm{c}}$, Alessandro Franchin ${ }^{\mathrm{a}}$, Ismael K. Ortega ${ }^{\mathrm{a}}$, \\ Francesco Riccobono ${ }^{\mathrm{b}}$, Jonathan Duplissy ${ }^{\mathrm{a}}$, Matti Rissanen ${ }^{\mathrm{a}}$, Mikko \\ Sipilä ${ }^{\mathrm{a}}$, Tuukka Petäjäa ${ }^{\mathrm{a}}$, Markku Kulmala ${ }^{\mathrm{a}}$, Neil M. Donahue ${ }^{\mathrm{d}}$, Douglas R. \\ Worsnop $^{\mathrm{a}, \mathrm{e}}$ and the CLOUD collaboration
${ }^{a}$ Department of Physics, University of Helsinki, P.O. Box 64, FI-00014 University of Helsinki, Finland
${ }^{b}$ Laboratory of Atmospheric Chemistry, Paul Scherrer Institut, 5232 Villigen PSI, Switzerland
${ }^{c}$ Institute for Atmospheric and Environmental Sciences, Goethe University Frankfurt, Altenhöferallee 1, 60438 Frankfurt am Main, Germany
${ }^{d}$ Center for Atmospheric Particle Studies, Doherty Hall 1106, Carnegie Mellon University, Pittsburgh, PA 15217, USA
${ }^{e}$ Aerodyne Research, Inc., 45 Manning Road, Billerica, MA 01821, USA

\begin{abstract}
The mechanisms behind the nucleation of vapors forming new particles in the atmosphere had been proven difficult to establish. One main aim of the CLOUD experiment was to explore in detail these first steps of atmospheric new particle formation by performing extremely well controlled laboratory experiments. We examined nucleation and growth in the presence of different mixtures of vapors, including sulfuric acid, ammonia, dimethylamine, and oxidation products of pinanediol or $\alpha$-pinene. Among the employed state-of-the-art instrumentation, a high-resolution mass spectrometer that directly sampled negatively charged ions and clusters proved particularly useful. We were able to resolve most of the chemical compositions found for charged sub-2nm clusters and to observe their growth in time. These compositions reflected the mixture of condensable vapors in the chamber and the role of each individual vapor in forming sub-2nm clusters could be explored. By inter-comparing between individual experiments and ambient observations, we try to establish which vapors participate in nucleation in the actual atmosphere, and how.
\end{abstract}

Keywords: clusters, ions, nucleation, mass spectrometry, CLOUD, oxidized organics

PACS: $36.40 . \mathrm{Wa}, 36.40 .-\mathrm{c}, 34.50 . \mathrm{Gb}, 34.50 .-\mathrm{s}, 82.80 . \mathrm{Rt}$, 82.60.Nh, 82.70.Rr, 92.60.Mt

\section{INTRODUCTION}

The formation of new aerosol particles in the atmosphere plays an important role in controlling the climate via several mechanisms. For instance, particles larger than about $50 \mathrm{~nm}$ can act as cloud condensation nuclei $(\mathrm{CCN})$, i.e. as seeds for the condensation of water forming cloud droplets. The concentrations of $\mathrm{CCN}$ therefore

Nucleation and Atmospheric Aerosols

AIP Conf. Proc. 1527, 298-301 (2013); doi: 10.1063/1.4803262

(C) 2013 AIP Publishing LLC 978-0-7354-1152-4/\$30.00 
influence cloud properties such as brightness and lifetime, which in turn affect climate. It is estimated that up to half of all $\mathrm{CCN}$ originate from the formation of sub-2 $\mathrm{nm}$ particles from vapors (nucleation) and their subsequent growth by the condensation of vapors (1). However, the mechanisms are still poorly understood in the details, particularly the critical first steps of atmospheric nucleation.

It is well established that atmospheric nucleation involves sulfuric acid $\left(\mathrm{H}_{2} \mathrm{SO}_{4}\right)$ (2). However, $\mathrm{H}_{2} \mathrm{SO}_{4}$ alone cannot account for the rates of formation (nucleation rates) and growth observed in the atmosphere, because it is too scarce. Most likely, $\mathrm{H}_{2} \mathrm{SO}_{4}$ molecules are stabilized in the formation of initial clusters by molecules of water, bases, such as ammonia and amines $(3,4)$, or oxygenated organic compounds that remain to be identified (5). It is challenging to establish the vapors and mechanisms that are involved in nucleation under certain atmospheric conditions due to the low concentrations of all participating vapors (except water). Also a wide range of compounds may be involved in view of the multitude of oxygenated organics formed by the oxidation of volatile organic compounds emitted into the atmosphere.

We aimed at determining the detailed processes of atmospheric nucleation by performing well-controlled laboratory experiments at the Cosmics Leaving OUtdoor Droplets (CLOUD) facility at CERN. Nucleation was investigated in a variety of potentially atmospherically relevant conditions that were reproduced in the CLOUD aerosol chamber. Key to unraveling in detail how nucleation proceeds were the very clean conditions provided by the CLOUD chamber, the precise control of these conditions, plus a suite of state-of-the-art instrumentation to measure gas and aerosol phase properties. In particular, novel mass spectrometric techniques were employed, enabling us to gain a view on the formation of sub- $2 \mathrm{~nm}$ clusters.

\section{METHOD}

The central part of the CLOUD facility is the CLOUD aerosol chamber, a $26.1 \mathrm{~m}^{3}$ stainless-steel cylinder. The facility is able to provide conditions exceptionally clean of contaminant compounds, crucial for performing experiments with extremely low concentrations of critical vapors. Most experimental parameters, such as temperature and trace gas concentrations can be precisely controlled. On demand, UV lights can initiate photolytic, mainly oxidizing reactions, such as the oxidation of sulfur dioxide to $\mathrm{H}_{2} \mathrm{SO}_{4}$. Additionally, the chamber can be exposed to a $\pi^{+}$beam provided by the CERN Proton Synchrotron to simulate varying intensities of galactic cosmic rays and study their effects. The instruments were arranged around the chamber and continuously sample its contents while it is filled with artificial air and trace gases at about $100 \mathrm{~L} / \mathrm{min}$.

Experiments were performed for different mixtures of vapors that would lead to nucleation. These mixtures comprised $\mathrm{H}_{2} \mathrm{SO}_{4}$, plus one or a combination of the following: ammonia $\left(\mathrm{NH}_{3}\right)$, dimethylamine $\left(\mathrm{C}_{2} \mathrm{H}_{7} \mathrm{~N}\right.$, DMA), pinanediol $\left(\mathrm{C}_{10} \mathrm{H}_{18} \mathrm{O}_{2}\right.$, PD), $\alpha$-pinene $\left(\mathrm{C}_{10} \mathrm{H}_{16}, \mathrm{AP}\right)$. AP served as an example of a typical volatile organic compound found in biogenic emissions. Its oxidation products are hypothesized to be able to participate in the first steps of new particle formation in the atmosphere. PD served as surrogate compound that can be oxidized to similar compounds by hydroxyl radicals $(\mathrm{OH})$ only. Oxidation processes in the chamber were chiefly initiated by 
reactions with $\mathrm{OH}$ and ozone $\left(\mathrm{O}_{3}\right)$. They could be modified by direct control over the injections of $\mathrm{O}_{3}$, hydrogen $\left(\mathrm{H}_{2}\right.$, as $\mathrm{OH}$ scavenger) and nitrous acid (HONO, to produce $\mathrm{OH}$ also without $\mathrm{O}_{3}$ ). Nucleation studies were performed at various temperatures (mostly $5{ }^{\circ} \mathrm{C}$ ), relative humidities (mostly 38\%) and beam intensity.

Most results presented here were obtained by using an Atmospheric Pressure interface Time-Of-Flight mass spectrometer (APi-TOF). The instrument was described in detail previously (6). It is able to sample ions directly from atmospheric pressure. The ions enter the instrument through a critical orifice and are then guided by quadrupoles and ion lenses through a series of differentially pumped chambers to the Time-Of-Flight region. The vacuum increases gradually to a final pressure of $10^{-6}$ mbar. Typically a mass accuracy of $<10 \mathrm{ppm}$ and a resolution $>5000 \mathrm{Th} / \mathrm{Th}$ were obtained. This performance allowed us to determine or effectively constrain the elemental compositions of ions and ion clusters, depending on the signal-to-noise ratio and the complexity of the obtained ion mass spectra. The useful range of the spectra reached up to mass-to-charge ratios of about $3300 \mathrm{Th}$, i.e. $3300 \mathrm{Da}$ for singly charged ions, corresponding to up to about $2 \mathrm{~nm}$ in mobility-equivalent diameter. At CLOUD, several APi-TOFs were in use. The APi-TOF mainly used for research presented here was operated in negative ion mode. No dedicated ionization of the sample was performed, and only anions charged in the CLOUD chamber were detected.

\section{RESULTS AND DISCUSSION}

One of the simplest nucleating mixtures we investigated at was that of $\mathrm{H}_{2} \mathrm{SO}_{4}$ and $\mathrm{NH}_{3}$ (and water). For this system, nucleation rates comparable to those observed in the atmosphere's boundary layer were not obtained at corresponding conditions of temperature and $\mathrm{H}_{2} \mathrm{SO}_{4}$ concentrations, even for $>1 \mathrm{ppb}$ of $\mathrm{NH}_{3}$ (3). However, the results obtained from APi-TOFs allowed us to observe the growth of clusters from single-molecule to $2 \mathrm{~nm}$ (mobility-equivalent diameter) by the step-wise addition of $\mathrm{NH}_{3}$ and $\mathrm{H}_{2} \mathrm{SO}_{4}$ molecules, roughly following a 1:1 ratio for experimental conditions closest to those in the boundary layer (Fig. 1).

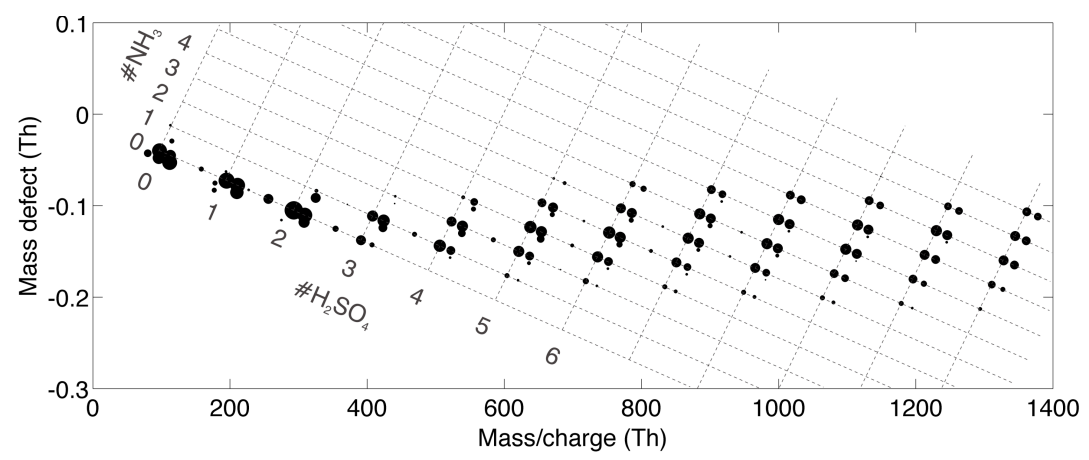

FIGURE 1. Spectrum for negatively charged clusters during mainly ion-induced nucleation at $19{ }^{\circ} \mathrm{C}$, $\left[\mathrm{H}_{2} \mathrm{SO}_{4}\right]=1.110^{8} \mathrm{~cm}^{-3}$ and $\left[\mathrm{NH}_{3}\right]=0.8 \mathrm{ppb}$. Marker diameters are proportional to $\left.\log _{10}(\operatorname{counts~s})^{-1}\right)$.

Clusters form starting from mainly $\mathrm{HSO}_{4}{ }^{-}$or $\mathrm{HSO}_{5}{ }^{-}$(the inlaid grid is shown for the former case), and grow by the addition of $\mathrm{H}_{2} \mathrm{SO}_{4}$ and $\mathrm{NH}_{3}$ molecules. 
In those first, as well as in subsequent nucleation experiments, growing ion clusters were observed by the APi-TOF. The addition of DMA, or different kinds of oxidized organics, or both, into the chamber consistently reflected on the composition of these clusters, while altering nucleation and growth rates. For instance, clusters involving oxidation products of PD or AP were observed up to $1500 \mathrm{Th}$, depending on the experimental conditions. This range corresponds to most or all of the sub-2 nm range (in terms of mobility-equivalent diameter), which is where the processes critical to nucleation take place. We were able to identify the most important clusters in those spectra. More information could be extracted from their development in time, which was obtainable at a resolution of $30 \mathrm{~s}$.

All these results give detailed insight into the formation mechanisms of molecular ion clusters from the gas-phase, processes directly connected to nucleation. Of particular interest is the inter-comparison of APi-TOF results for different conditions, especially for different mixtures of condensable compounds in the chamber, to see which compounds gain importance for nucleation at which concentrations. Eventually, comparisons are made also to ambient observations, as the same or very similar compounds compete for contributing to nucleation probably also in the atmosphere.

\section{ACKNOWLEDGMENTS}

CERN's support of CLOUD by providing technical and financial resources and a particle beam from the CERN Proton Synchrotron is gratefully acknowledged. This research has received funding from the EC Seventh Framework Programme (Marie Curie Initial Training Network "CLOUD-ITN" no. 215072, MC-ITN "CLOUDTRAIN" no. 316662, and ERC-Advanced "ATMNUCLE" grant no. 227463), the German Federal Ministry of Education and Research (project nos. 01LK0902A and 01LK1222A), the Swiss National Science Foundation (project nos. 200020_135307 and 206620_130527), the Academy of Finland (Center of Excellence project no. 1118615), the Academy of Finland (135054, 133872, 251427, 139656, 139995, 137749, 141217, 141451), the Finnish Funding Agency for Technology and Innovation, the Nessling Foundation, the Austrian Science Fund (FWF; project no. P19546 and L593), the Portuguese Foundation for Science and Technology (project no. CERN/FP/116387/2010), the Swedish Research Council, Vetenskapsrådet (grant 2011-5120), the Presidium of the Russian Academy of Sciences and Russian Foundation for Basic Research (grants 08-02-91006-CERN and 12-02-91522-CERN), and the U.S. National Science Foundation (grants AGS1136479 and CHE1012293).

\section{REFERENCES}

1. J. Merikanto, D. V. Spracklen, G. W. Mann, S. J. Pickering and K. S. Carslaw, Atmos. Chem. Phys. 9, 8601-8616 (2009).

2. R. J. Weber et al., Chem. Eng. Comm. 151, 53-64 (1996).

3. J. Kirkby et al., Nature 476, 429-433 (2011).

4. T. Kurtén, V. Loukonen, H. Vehkamäki and M. Kulmala, Atmos. Chem. Phys. 8, 4095-4103 (2008).

5. A. Metzger et al., Proc. Natl. Acad. Sci. USA 107, 6646-6651 (2010).

6. H. Junninen et al., Atmos. Meas. Tech. 3(4), 039-1053 (2010). 